\title{
Luz amarilla de infancia, sonido verde de arquitectura, viento azul de educación
}

\section{Jorge Raedó*}

Recepción original: 6 de octubre de 2020

Aceptación: 14 de enero de 2021

Publicación: 1 de junio de 2021

Temps d'Educació dedica este número a proyectos e investigaciones que aúnan las palabras «infancia», «arquitectura» y «educación» en los Países Catalanes.

¿Qué es Infancia? ¿Qué es Arquitectura? ¿Qué es Educación? Tres preguntas que acotan un amplio campo de investigación y acción en muchos países. Docentes, pedagogos, arquitectos, artistas, antropólogos, biólogos, economistas... observan necesidades concretas de las infancias que les rodean y quieren solventarlas. El trabajo interdisciplinar, el estudio de la labor pasada y presente de los colegas vecinos y foráneos, la escucha atenta de la voz de nuestra infancia, son imprescindibles para alcanzar el objetivo.

Hay muchos proyectos en el mundo que aúnan las palabras «infancia»', «arquitectura» y «educación». Los clasificamos así:

- Infraestructura educativa. Un buen espacio de aprendizaje nacerá de un proyecto pedagógico concreto. El proyecto pedagógico es la mano, la infraestructura es el guante que se adapta a esa mano. Consideramos los espacios interiores y exteriores, su relación abierta con el barrio, la dinámica social de las familias. El proyecto pedagógico es un árbol de extensas ramas que sobrepasan los límites de la infraestructura construida.

- Materiales didácticos desde el diseño y la arquitectura. Hay una larga tradición de materiales nacidos de conceptos arquitectónicos, geométricos y estéticos para potenciar el aprendizaje en la infancia. Froebel es el más conocido, cuya concepción del Universo y la vida determinaron sus piezas y procesos didácticos. Desde entonces, decenas de pedagogos, artistas y arquitectos han diseñado juegos con vocación lúdica o curricular. Otros materiales didácticos son audiovisuales, publicaciones, websites Open Educational Resources...

- Aprendizaje de la arquitectura como lenguaje. Cursos y talleres para que la infancia aprenda arquitectura, igual que aprende pintura, música, danza, teatro, cine... Las artes son lenguajes. La infancia aprende a leer y a escribir. También aprende disciplinas artísticas que amplían su percepción del mundo y su capacidad de expresión.

$\left(^{*}\right) \quad$ Jorge Raedó (Zaragoza, España 1969) es artista y profesor de arte para infancia y juventud. Vivió en Cataluña desde 1975 a 2011 . Sus proyectos con infancia desde 2008 están resumidos en el blog www.osamenor.com, donde destacan «¿Qué es Arquitectura?», las óperas con alumnos de colegios finlandeses promovidas por la asociación Rakennetaan kaupunki!, «Amag! Revista de Arquitectura para Niños», «Ludantia. I Bienal Internacional de Educación en Arquitectura para la Infancia y Juventud». Dirección electrónica: jorge.raedo@live.com

(1) Por economía de lenguaje, donde digo «infancia» me refiero a infancia y juventud. La Convención de los Derechos del Niño de la ONU define «niño» como la persona por debajo de los 18 años. 
Crecer es construir la narración personal que se suma a la narración colectiva. Tal construcción se hace con la expresión a través de las artes.

- Proyectos de participación. Procesos donde la infancia es protagonista de la trasformación de su mundo. Hay proyectos de participación para que la infancia aprenda sus derechos y obligaciones como ciudadanos en el manejo de las urbes y territorios donde viven. Otros proyectos quieren que la infancia aprenda procesos de diseño participativo para la transformación física de su entorno, técnicas y métodos que finalizan en la construcción de lo proyectado.

- Regeneración urbana. Proyectos que suceden en varios espacios de la ciudad: caminos escolares, zonas de juego, parques, trasformación de espacio público para adaptarse a las necesidades de los más pequeños y sus cuidadores, intervenciones de diseño y auto-gestión con jóvenes, espacios hospitalarios para ayudar a la sanación de la infancia... Los rincones de la localidad son susceptibles de apropiación infantil.

- El cerebro infantil. Investigaciones recientes sobre el cerebro han aportado luz sobre al funcionamiento del cerebro, cómo construimos la visión, cómo imaginamos mapas que nos orientan, cómo percibimos el espacio. La neurociencia aporta datos para entender los procesos de aprendizaje en cada edad. La neuroarquitectura quiere que estos conocimientos se traduzcan en diseños arquitectónicos que satisfagan mejor necesidades específicas de cada etapa de la vida.

- Formación de profesorado. Publicaciones, cursos, talleres y otras actividades para transmitir al profesorado de la infancia las experiencias que aportan los grupos citados. La arquitectura, donde incluimos diseño, urbanismo, paisaje, territorio... suele ser materia poco explorada por la ciudadanía y por el profesorado. La formación continua muestra las relaciones existentes entre la arquitectura, la infancia y la educación.

A menudo los grupos se mezclan entre sí. Los proyectos para el aprendizaje de la arquitectura como lenguaje se convierten en procesos de diseño participativo donde la infancia vive el estudio de un problema, imagina la solución a través de herramientas del diseño y finalmente se convierte en una realidad espacial. Proyectos de regeneración urbana son hechos para la infancia pero sin ella, o con la infancia. La infraestructura educativa no suele tener en cuenta la voz de la infancia, aunque debería tenerla en cuenta. De hecho, bastante infraestructura educativa nueva no tiene en cuenta ni la voz del profesorado: nacen así edificios poco aptos para las tendencias pedagógicas contemporáneas. El material didáctico se mezcla fácilmente con el aprendizaje de la arquitectura como lenguaje.

El contexto donde se hacen los proyectos influye en la personalidad de los mismos. No es lo mismo trabajar en horario escolar dentro de la malla curricular que trabajar fuera del horario académico. No es lo mismo trabajar en un colegio de un barrio vulnerable de Barranquilla, que en un colegio del Eixample de Barcelona. Los procesos, estrategias y ritmos de aprendizaje serán distintos.

¿Hay consenso sobre qué es arquitectura, y por lo tanto, qué es aprenderla? Hay tantas comprensiones de la arquitectura como personas. Todos la vivimos desde antes de nacer, todos sabemos qué es sentirse bien o mal en un espacio, qué es una ciudad agradable u hostil, un territorio fácil o difícil de comprender. Quien enseña arquitectura tiene claro qué es la disciplina para sí mismo y qué transmite a la infancia. 
La arquitectura, como lenguaje, sólo tiene sentido como narración personal y colectiva: nos ubica en el espacio y en el tiempo, nos enraíza en un ayer donde anida el presente de espejismos futuros.

La narración constituye la unidad lingüística que lleva consigo sus propios límites. En la narración, como en el juego, el universo está limitado, el contexto está creado y dado, de modo que los acontecimientos de la narración pueden captarse y su sentido comprenderse con mayor rapidez que los hechos situados en un mundo menos hospitalario, con límites imprecisos. (Egan, 1991, p. 97)

Los seis artículos aquí reunidos muestran seis experiencias: una de Baleares, dos de Valencia y tres de Cataluña. Uno es de formación del profesorado, otro trata de infraestructura educativa y cuatro hablan de aprendizaje de la arquitectura como lenguaje. Fueron escogidos por su relevancia y trayectoria consolidada en los Países Catalanes.

Ricard Huerta, autor del texto «Disseny d'entorns per educar en diversitat i fomentar la inclusió», tiene larga trayectoria como profesor en la Universitat de València. Su alumnado es principalmente del Grado de Maestro de Primaria.

Su texto constata la dificultad del aprendizaje de las artes en la educación obligatoria de Primaria y Secundaria en España. El currículum oficial ha quitado espacio y tiempo a las artes en favor de materias que se suponen más útiles para la infancia una vez sean adultos, como las matemáticas, ciencias, idiomas extranjeros... Si bien estos saberes son imprescindibles, de poco sirve usar un ordenador si no sabes por qué lo usas. Las Humanidades y las Artes pierden terreno en la educación obligatoria, como las aguas desaparecen ante el avance del desierto.

Ricard Huerta y grupo CREARI d'Investigació en Pedagogies Culturals de la Universitat de València llevan años reflexionando sobre las artes como lenguajes y expresión, como vehículo de inclusión y cohesión, como la luz que baña penumbras personales o colectivas.

Intento transmetre la passió per educar des del respecte. Formar la sensibilitat inclou el coneixement dels entorns. I entre els entorns que proposo em centraré en 7 entorns per educar en diversitat que són els següents: I'alfabet; la ciutat; Museari; el cos; la por; la mort; i el cinema. (Huerta)

El espacio educador no sólo es la infraestructura construida, o el uso que damos al mobiliario y materiales didácticos. El espacio educador nace en la cabeza y el corazón del profesor que lo construye con los alumnos mediante el diálogo.

Los siete entornos educativos que propone Huerta abren espacios imaginarios dentro de uno mismo, apoyándose en el contexto cultural próximo, donde buscamos, hurgamos, tropezamos... hasta dar con el camino de salida en forma de expresión estética.

Hem d'estar molt atents i treballar units per despullar les nostres aules de pors i ocultacions, apostant al mateix temps per una educació com a motor de canvi social. En aquest sentit, el professorat ha d'implicarse al màxim per lluitar contra el bullying i tot tipus d'assetjament o abús motivats per atacs a la diversitat. No perdem de vista que una situació de precarietat com l'actual resulta molt procliu als abusos per part del poder. (Huerta)

Carme Cols i Pitu Fernàndez fueron profesores de Infantil y Primaria en Cataluña durante más de cuarenta años. Ahora, ya jubilados y autodenominándose El Safareig, promueven la mejora de los patios escolares en decenas de localidades del Estado español. 
Ellos consideran el patio escolar como un espacio educador más de la infraestructura. Por lo tanto, el patio responde a una visión pedagógica, a un proyecto educativo y a criterios arquitectónicos. Si falta uno de los tres ingredientes, el patio no funciona, como no funcionaría ningún otro espacio del centro educativo.

L'espai del pati és una finestra oberta al món. El seu plantejament ens permet intuir la vida de l'escola des de punts de vista i aspectes diferents. És un dels primers espais en què les famílies es fixen per escollir escola. Un espai emotiu per les percepcions i els records que la majoria dels adults han viscut. És un espai comunitari i una porta oberta a la participació en el municipi com a territori col-lectiu. Pot ser un lloc en el qual la naturalesa articuli i faci visibles diferents zones, convidant a ser habitat i oferint la possibilitat de compartir experiències en un ambient ric en possibilitats de joc, d'aprenentatge, de relacions, de convivència, de creativitat. Un espai de vida i per a la vida en el qual apostem per fer possible una escola agradable, on nens, mestres i famílies es trobin bé, tant en l'espai interior com a l'exterior de l'escola. (Carme Cols i Pitu Fernàndez)

El Safareig promueve patios llenos de vegetación, tierra, areneros, juegos de troncos y piedras, cabañas, puentes, caminos, senderos, fuentes, penumbras, sombras, recovecos... apuntes físicos que insinúan ambientes, sensaciones, aproximaciones y soledades voluntarias. Son lugares que abrazan imaginaciones de todo tipo, observaciones y reflexiones sin exclusión, el hogar de toda la infancia.

El patio ideal se relaciona con los espacios interiores del jardín de infancia o colegio, siendo el tiempo y el ritmo diario del centro el hilo que cose el adentro con el afuera, un tapiz que se extiende al barrio y la ciudad. El patio está hecho por todos y para todos. El patio se hace cada día, se transforma con nosotros.

Rubèn Pineda es arquitecto y profesor de Primaria, Secundaria y Bachillerato en Cataluña. Su artículo «L'arquitectura en l'educació obligatòria, mitjà o finalitat?» reflexiona sobre lo que esta disciplina artística aporta a las metodologías y los procesos de aprendizaje.

Pineda considera que la aprobación en el Parlamento de Cataluña de la Ley de Arquitectura en 2017 e impulsada por el Col·legi Oficial d'Arquitectes de Catalunya, es una oportunidad para introducir al disciplina en los centros de educación obligatoria. ¿Cómo hacerlo?

(...) l'arquitectura entesa com a font d'aprenentatge competencial és sinònim de treball col.laboratiu i relació social, i permet implicar activament l'alumnat en els processos d'aprenentatge, a través de les emocions com a part integral. L'arquitectura disposa possibilitats enormes per bastir connexions horitzontals entre àrees de coneixement i activitats, promovent la translació de les estructures de coneixement a noves situacions, i entenent la seva magnitud més enllà dels continguts. (Pineda)

La doble faceta de Pineda, como arquitecto y maestro, otorga a su labor gran fortaleza pedagógica. La segunda parte del artículo explica ejemplos de sus proyectos con los alumnos de los centros donde ha trabajado. Destaco la división que hace de esos proyectos según su función principal:

1.Capacitativa: activitats que fonamentalment es proposen el desenvolupament d'habilitats i capacitats per tal de transcendir els límits intel-lectuals dels alumnes.

2.Interpretativa: amb finalitat analítica i de comprensió de l'entorn i del patrimoni construït a partir de la descomposició conceptual dels seus paràmetres i elements constitutius.

3.Transformativa: quan es mobilitza la crítica constructiva per tal de qüestionar, evolucionar, tergiversar i replantejar un disseny arquitectònic, urbanístic o de producte. (Pineda)

El proyecto transformativo «Salvem Cal Valent» sobresale por la complejidad de sus ingredientes. Los alumnos estudian el problema arquitectónico y social del edificio en 
desuso, proponen soluciones mediante el diseño, tejen la red vecinal que dialogará con las instituciones para transformar el lugar para el bien común.

El Globus Vermell es un grupo de profesionales catalanes que promueve la difusión de la arquitectura en la sociedad. Algunos de sus proyectos se dirigen a la infancia y juventud.

Joan Vitòria, fundador del grupo junto con Mari Carmen Artero, escribe un texto en dos partes. La primera explica su labor como difusor de la cultura arquitectónica, necesaria para conocer el porqué de las ciudades donde vivimos, y para controlar las decisiones públicas sobre arquitectura y urbanismo que nos afectan. Trabajar con infancia tendrá el mismo objetivo.

\section{Difondre el coneixement i les eines adequades per desenvolupar consciència i esperit crític sobre els en- torns construïts és l'acció que permetrà donar resposta a aquest repte. I és especialment important trans- metre aquestes eines des de l'etapa formativa bàsica per tal de contribuir a forjar una ciutadania conscient, responsable i amb un criteri fonamentat. (Vitòria)}

El Globus Vermell entiende la cultura arquitectónica como un sistema global que nos envuelve, una atmósfera que nos da la vida y a la vez nosotros configuramos con nuestras acciones. La ecología, natural y ética, es pilar básico de la sociedad.

La segunda parte del texto describe el planteamiento del programa Arqui-escola para los colegios catalanes. Una iniciativa que cree en la arquitectura como herramienta para la transformación social.

L'objectiu principal de l'Arqui-escola és contribuir a la formació d'un esperit crític ja des de la infància per tal que infants i joves esdevinguin persones madures per prendre part de forma constructiva en el disseny col·lectiu dels entorns urbans. (Vitòria)

Arqui-escola, programa educativo para introducir la arquitectura en el currículum educativo, está promovido por el Col-legi Oficial d'Arquitectes de Catalunya en cumplimiento de la nueva Ley de Arquitectura aprobada en Cataluña en 2017. El programa mezcla la disciplina arquitectónica con objetivos sociales y éticos, junto a procesos de creación. Una apuesta sofisticada y flexible que entra en los colegios de la mano del profesorado. Siempre que se mezcla profesorado de la educación obligatoria y arquitectos en un proyecto educativo para infancia surgen retos básicos: la sincronización de los objetivos pedagógicos, la terminología y el calendario.

Por otra parte, Arquitectives trabaja en Mallorca, principal isla de las Baleares. La vida insular confiere una percepción particular de la vida en local, alejada de comunidades más grandes. A la vez, ellos son los representantes de España ante la sección «Arquitectura e Infancia» de la Unión Internacional de Arquitectos desde 2012.

Pablo Amor y Cristina Llorente, creadores de Arquitectives, promueven la visión ecosistémica de la arquitectura. Un ecosistema con todas sus capas: natural, cultural, económica, tecnológica... Si la arquitectura es un lenguaje, como todas las otras disciplinas artísticas, ¿es lo mismo enseñar arquitectura en Mallorca que en Australia o Tanzania? Si bien la arquitectura tiene morfologías diversas según zonas del planeta, en esencia, según Amor y Llorente, es un lenguaje universal.

La arquitectura ha sido tradicionalmente, como cualquiera de las otras artes, un campo reservado a los expertos en la materia, en general arquitectos e historiadores o teóricos del arte. La diferencia con el resto de las artes es que como ninguna otra nos acompaña en el día a día. La podemos disfrutar o sufrir, es algo tan cercano a nosotros que no necesitamos encontrarnos con ella visitando un museo, como ocurre con 
la pintura o la escultura, o asistiendo a un auditorio, en el caso de la música. Esa cercanía y relación constante que con ella establecemos, la mayor parte del tiempo de manera inconsciente, debería poder hacernos más críticos con la construcción de la sociedad que la soporta. (Amor y Llorente)

Los proyectos educativos de Arquitectives proponen las herramientas básicas de la disciplina: vivienda, ciudad, estructuras, geometría, historia y patrimonio, escala y proporción, percepción, medio ambiente y paisaje... Ellos mezclan la arquitectura con otros campos de conocimiento: las matemáticas, la ingeniería, la ecología, la economía, el paisaje, la psicología, la historia, el arte, la cultura, la sociedad, son algunos ejemplos.

Todos los recursos son buenos para provocar la reflexión de alumno sobre su condición personal, colectiva e histórica. Ecosistema es espacio y tiempo, es deberes y derechos, es mi bien y el tuyo. El estudio de la arquitectura ayuda a entendernos y a proyectarnos en el mundo. El estudio de ciertas áreas del currículum obligatorio a través de la arquitectura es una buena estrategia.

Silvana Andrés, co-fundadora de Arquilecturas junto con Sonia Rayos en Valencia, es artista plástica y maestra. Nuevamente, la combinación de las dos facetas profesionales da fuerza y eficiencia al proyecto educativo.

La autora hace referencia a Vygoski, Piaget, Montessori, Ausubel, Pestalozzi, Pikler, Aucouturier, Malaguzzi y Freinet para fundamentar sus proyectos de educación en arquitectura para infancia en horario escolar y extra-escolar. Ella observa al niño como un todo: cuerpo, espacio, tiempo, contexto social y ambiental. Son partes que sumadas dan más que las partes sueltas.

Como los otros autores, Andrés quiere que la infancia aprenda a observar críticamente, siendo consciente de su papel en la sociedad. Las artes son fundamentales para este fin. Noble objetivo. ¿La arquitectura ayuda en ese cometido? Depende del profesorado, referente ético para sus alumnos. El profesor es quien crea el ambiente de aprendizaje, esa atmósfera que permite respirar al alumno, es decir, aprender. El espacio construido, el mobiliario y el material didáctico son personajes secundarios que el profesor usará de acuerdo a sus objetivos pedagógicos. Pero en realidad, ¿todo esto está pasando en los colegios de España?

\footnotetext{
De nada sirven las maravillosas palabras introductorias en las que el currículo señala que «el proceso de aprendizaje en el ser humano no puede estar alejado del desarrollo de sus facetas artísticas». (BOE-A-20142222, 2014, p. 46). La realidad es que entre los 6 y los 11 años el alumnado dispone de una única sesión semanal para desarrollar la mayoría de estas experiencias. En la etapa más adecuada para su desarrollo la presencia de la educación artística es meramente testimonial. Mientras tanto antes de pasar a secundaria muchos de nuestros alumnos y alumnas se abrirán cuenta en Instagram o en cualquier otra red social. La Lomce me devuelve a La clave de los sueños de Magritte, dónde las palabras no se correspondían con los objetos. (Andrés)
}

El trabajo diario de Arquilecturas despierta la visión global en la infancia, promueve la intencionalidad de la mirada, estimula el juego para aprender conceptos ligados a la vida cotidiana; reflexiona sobre el espacio jugando, y así crea el espacio que juegan. Andrés concluye con esta cita de Freinet:

No hay nada tan exaltante como un lugar de trabajo, sobre todo cuando en él se construyen personas. Los constructores, las constructoras, nos comprenderán y nos ayudarán. (Célestin Freinet, 1986, p. 122-123)

¿Qué es arquitectura? Una pregunta sin solución exacta. La luz amarilla de mi infancia catalana dibuja la penumbra con una respuesta: la arquitectura es gravedad, símbolo y hogar. 
La arquitectura es gravedad porque todos los objetos con masa son atraídos entre sí, las construcciones tienen que vencer esa atracción, no desmoronarse... Es gravedad porque el deseo de las personas y sociedades alteran el tejido del espacio-tiempo y configuran el mundo construido donde vivimos.

La arquitectura es símbolo porque nos dicen quiénes somos. El Panteón de Roma es un muro circular y una cúpula con un agujero en su centro. Es buena técnica porque no se ha caído en dos mil años. A la vez, es el símbolo de una civilización de la que somos herederos millones de ciudadanos.

La arquitectura es hogar. Una construcción, un pueblo, un paisaje son hogar cuando nos dicen de dónde venimos y a dónde vamos. El hogar nos da el sentido, es la hoja donde escribimos nuestra narración.

Hoy la arquitectura suena verde, como los pinos mediterráneos de Tarragona, afirmativos junto al mar. El olor del tomillo mezclado con el de la sal es el horizonte de aventuras. La infancia es el espacio educador. Tal vez el único. El viento pasa las hojas del libro donde escribo. Viento azul de educación.

\section{Referències}

Egan, K. (1991) La comprensión de la realidad en educación infantil y primaria. Madrid, Ministerio de Educación y Ciencia y Ediciones Morata.

Freinet, C. (1986) Parábolas para una pedagogía popular. Barcelona, Planeta-Agostini. 